\title{
Mitochondrial Membrane Potential in Axons Increases with Local Nerve Growth Factor or Semaphorin Signaling
}

\author{
Jessica Verburg and Peter J. Hollenbeck \\ Department of Biological Sciences, Purdue University, West Lafayette, Indiana 47906
}

\begin{abstract}
Neurons concentrate mitochondria at sites in the cell that have a high demand for ATP and/or calcium buffering. To accomplish this, mitochondrial transport and docking are thought to respond to intracellular signaling pathways. However, the cell might also concentrate mitochondrial function by locally modulating mitochondrial activity. We tested this hypothesis by measuring the membrane potential of individual mitochondria throughout the axons of chick sensory neurons using the dye tetramethylrhodamine methylester (TMRM). We found no difference in the TMRM mitochondrial-to-cytoplasmic fluorescence ratio $\left(F_{\mathrm{m}} / F_{\mathrm{c}}\right)$ among three functionally distinct regions: axonal branch points, distal axons, and the remaining axon shaft. In addition, we found no difference in $F_{\mathrm{m}} / F_{\mathrm{c}}$ among stationary, retrogradely moving, or anterogradely moving mitochondria. However, $F_{\mathrm{m}} / F_{\mathrm{c}}$ was significantly higher in the lamellipodia of growth cones, and among a small fraction of mitochondria throughout the axon. To identify possible signals controlling membrane potential, we used beads covalently coupled to survival and guidance cues to provide a local stimulus along the axon shaft. NGF- or semaphorin 3A-coupled beads caused a significant increase in $F_{\mathrm{m}} / F_{\mathrm{c}}$ in the immediately adjacent region of axon, and this was diminished in the presence of the PI3 (phosphatidylinositol-3) kinase inhibitor LY294002 [2-(4-morpholinyl)-8-phenyl-4H-1-benzopyran-4-one] or the MAP (mitogen-activated protein) kinase inhibitor U0126 (1,4-diamino-2,3-dicyano-1,4-bis[2-amino-phenylthio]butadiene), demonstrating that signaling pathways downstream of both ligands affect the $\Delta \Psi_{\mathrm{m}}$ of mitochondria. In addition, general inhibition of receptor tyrosine kinase activity produced a profound global decrease in $F_{\mathrm{m}} / F_{\mathrm{c}}$. Thus, two guidance molecules that exert different effects on growth cone motility both elicit local, receptor-mediated increases in membrane potential.
\end{abstract}

Key words: mitochondria; membrane potential; growth cone; axonal transport; cell signaling; growth factor

\section{Introduction}

The size and asymmetry of neurons result in a nonuniform distribution of demand for mitochondrial functions such as ATP synthesis and calcium homeostasis. As a result, neurons redistribute their mitochondria in response to immediate and local physiological conditions, both in vivo and in vitro (Hollenbeck and Saxton, 2005). Mitochondria are concentrated in areas of the neuron expected to have higher ATP consumption; indeed, synapses were first recognized ultrastructurally based in part on their high density of mitochondria (Palay, 1956; Hollenbeck and Saxton, 2005). Other such regions are active growth cones and axon branches (Morris and Hollenbeck, 1993; Ruthel and Hollenbeck, 2003; Miller and Sheetz, 2004), nodes of Ranvier (Berthold et al., 1993), myelination boundaries and demyelinated regions (Mutsaers and Carroll, 1998; Bristow et al., 2002), and sites of axonal protein translation (Martin et al., 1998). In addition, when the activity of synapses or entire tracts changes, the mitochondrial density changes in concert (for review, see Hollenbeck and Saxton, 2005). Furthermore, excluding mitochondria from some of

Received June 9, 2008; accepted July 1, 2008.

This work was supported by National Institutes of Health-National Institutes of Neurological Disorders and Stroke Grant NS027073.

Correspondence should be addressed to Peter J. Hollenbeck, Department of Biological Sciences, Purdue University, 915 West State Street, West Lafayette, IN 47906. E-mail: phollenb@purdue.edu. DOI:10.1523/JNEUROSCI.2614-08.2008

Copyright $\odot 2008$ Society for Neuroscience $\quad$ 0270-6474/08/288306-10\$15.00/0 these regions has profound effects on neuronal activity and synaptic plasticity (Li et al., 2004; Verstreken et al., 2005). Mitochondria are distributed within neurons by fast transport and docking interactions, both of which are likely to be regulated via specific cell signaling pathways (Ratner et al., 1998; Morfini et al., 2002, 2004; Chada and Hollenbeck, 2003, 2004; De Vos et al., 2003; Malaiyandi et al., 2005).

In this study, we asked whether neurons can regulate the amount of local mitochondrial function not only by positioning mitochondria in a particular axonal location but also by upregulating or downregulating the activity of those that are already present. If this were the case, we would expect that, under normal conditions, there would be significant intracellular variation in metabolic activity among mitochondria in the same neuron. Several studies using different measures of mitochondrial transmembrane potential $\left(\Delta \Psi_{\mathrm{m}}\right)$ have shown such variation, for example, between axonal and dendritic mitochondria (Overly et al., 1996), between axonal mitochondria moving in different directions (Miller and Sheetz, 2004), and in individual mitochondria, in an oscillating manner over time (Buckman and Reynolds, 2001). However, it is not known whether $\Delta \Psi_{\mathrm{m}}$, like mitochondrial transport, changes with local demands, nor whether intracellular signaling might regulate $\Delta \Psi_{\mathrm{m}}$ within the neuron. Here, we assessed $\Delta \Psi_{\mathrm{m}}$ in sensory neurons in culture using a mitochondrial-to-cytoplasmic dye fluorescence ratio $\left(F_{\mathrm{m}} / F_{\mathrm{c}}\right)$ under subquenching conditions. We measured variation in $F_{\mathrm{m}} / F_{\mathrm{c}}$ 
among functionally distinct regions of the neuron and different mitochondrial populations, and also assessed the response of $F_{\mathrm{m}} / F_{\mathrm{c}}$ to local and global signals. We find that $F_{\mathrm{m}} / F_{\mathrm{c}}$ within a single cultured neuron is remarkably uniform with one exception: it is significantly higher in active growth cones. We also find that a similar increase in $F_{\mathrm{m}} / F_{\mathrm{c}}$ can be produced by focal stimulation of the axon with two ligands, nerve growth factor (NGF) and semaphorin 3A (sema3A), that normally elicit growth cone responses (Mueller, 1999), and that inhibition of signaling pathways downstream of these ligands can induce a profound global depression of membrane potential.

\section{Materials and Methods}

Materials. Reagents were obtained from Sigma-Aldrich unless otherwise specified.

Cell culture. Dorsal root ganglia were dissected from the lumbosacral region of embryonic day 10 (E10) to E11 chick embryos, dissociated, and grown in supplemented L-15 medium as previously described (Bray et al., 1991; Morris and Hollenbeck, 1995; He and Baas, 2003). For cultures to be grown in serum-containing medium, ganglia were manually triturated in HBSS and plated on $25 \mathrm{~mm}$ round ethanol-cleaned glass coverslips that had been treated sequentially with $1 \mathrm{mg} / \mathrm{ml}$ poly-L-lysine $(20$ $\mathrm{min}$ ), $\mathrm{H}_{2} \mathrm{O}$, and $10 \mu \mathrm{g} / \mathrm{ml} \mathrm{laminin}$ (20 min). When cells were to be grown in defined F12 medium, they were triturated in medium rather than HBSS and were then plated on coverslips that had been treated either overnight at $4^{\circ} \mathrm{C}$ or $40 \mathrm{~min}$ at $37^{\circ} \mathrm{C}$ with $50 \mu \mathrm{g} / \mathrm{ml}$ fibronectin (Calbiochem) dissolved in PBS. Serum-containing medium was used for mitochondrial inhibitor experiments, comparisons of $F_{\mathrm{m}} / F_{\mathrm{c}}$ in different axonal regions, and comparisons between moving and stationary mitochondria, whereas defined F12 medium was used for experiments involving NGF or sema3A coupled to beads. Two different types of serum-containing medium were used. "C" medium consisting of L-15 (Invitrogen) plus $0.5 \%$ methyl cellulose, $10 \%$ fetal bovine serum (Atlanta Biologicals), $2 \mathrm{~mm}$ glutamine, $0.6 \%$ glucose, $100 \mathrm{U} / \mathrm{ml}$ penicillin/streptomycin, and $50 \mathrm{ng} / \mathrm{ml} \mathrm{NGF} \mathrm{(Alamone} \mathrm{Labs)} \mathrm{was} \mathrm{used} \mathrm{overnight} \mathrm{to}$ establish cultures. Cells were then transferred to "F+" medium, identical to $\mathrm{C}$ medium except without $0.5 \%$ methyl cellulose, during dye loading and imaging. For some experiments, the glucose in the medium was replaced with $4 \mathrm{~mm}$ sodium pyruvate. For experiments using beads covalently coupled to guidance molecules, we used a defined medium (Gallo et al., 1997; Chada and Hollenbeck, 2003, 2004) consisting of the following: F12 medium (Invitrogen) supplemented with $0.1 \mathrm{mg} / \mathrm{ml}$ apotransferrin, $2.5 \mathrm{mg} / \mathrm{ml} \mathrm{BSA}, 20 \mu \mathrm{g} / \mathrm{ml}$ insulin, 20 nм progesterone, 17.8 $\mu \mathrm{g} / \mathrm{ml}$ phospocreatine, $5 \mathrm{ng} / \mathrm{ml}$ sodium selenite, $2 \mathrm{~mm}$ glutamine, $4 \mathrm{~mm}$ sodium pyruvate, and buffered with $1 \mathrm{~mm}$ HEPES to $\mathrm{pH}$ 7. For overnight cultures, $90 \mathrm{ng} / \mathrm{ml} \mathrm{NGF}$ was added to the medium, whereas during bead incubation a concentration of $5 \mathrm{ng} / \mathrm{ml}$ NGF was used in the medium.

Dye loading. For determination of mitochondrial transmembrane potential (Scheffler, 1999; Nicholls and Budd, 2000), a $5 \mu \mathrm{M}$ stock of tetramethylrhodamine methyl ester (TMRM) (Invitrogen) in DMSO was diluted into $\mathrm{F}+$ medium to a final concentration of $20 \mathrm{~nm}$. Cultures were exposed to $20 \mathrm{~nm}$ TMRM for $20 \mathrm{~min}$ at $37^{\circ} \mathrm{C}$ to allow dye equilibration across the plasma and inner mitochondrial membranes (Johnson et al., 1980; Farkas et al., 1989; Scaduto and Grotyohann, 1999). To confirm the rate of equilibration of TMRM across the plasma membrane, cytoplasmic fluorescence was measured in axons and growth cones after incubation in $20 \mathrm{~nm}$ dye for times ranging from 2 to $20 \mathrm{~min}$. In both regions, cytoplasmic fluorescence reached its peak level within $2 \mathrm{~min}$ and increased no further, indicating that a 20 min incubation is more than adequate for dye equilibration. The matrix TMRM concentration of cells exposed in this way is subquenching, resulting in a direct relationship between fluorescence intensity and $\Delta \Psi_{\mathrm{m}}$ (Ward et al., 2000; Nakayama et al., 2002). For imaging, the medium was replaced with F+ containing 5 nM TMRM. Mitotracker Green FM (Invitrogen) was stored as a stock in DMSO and diluted to a final concentration of $50 \mathrm{~nm}$ in $\mathrm{F}+$ medium along with $20 \mathrm{~nm}$ TMRM. Cells were incubated in this mixture for $15 \mathrm{~min}$ before being transferred to F+ medium with $20 \mathrm{nM}$ TMRM but no Mitotracker and incubated for $5 \mathrm{~min}$ more to rinse out excess MitoTracker.
For microscopy, cells were transferred to F+ with 5 nM TMRM. JC-1 staining was performed as described previously (Overly et al., 1996).

Light microscopy. After mitochondrial dye loading, coverslips were mounted in a custom-made aluminum and Teflon holder or an aluminum Sykes-Moore chamber with enough F+/5 nM TMRM to fill the chamber $(\sim 1 \mathrm{ml})$. A Nikon TE300 inverted fluorescence microscope with a Hamamatsu ORCA cooled CCD camera was used to record images. A Texas Red and FITC filter set was used to visualize TMRM and MitoTracker Green respectively. Twelve-bit images were acquired through a $60 \times, 1.4$ numerical aperture oil-immersion objective, and choosing exposure times such that the brightest signals were at $\sim 75 \%$ saturation. JC-1 imaging was performed on a Bio-Rad MRC 600 confocal microscope, using excitation at $488 \mathrm{~nm}$ and simultaneous detection at 520 and $590 \mathrm{~nm}$. Mitochondrial movement was tracked and analyzed as described previously (Morris and Hollenbeck, 1993, 1995; Overly et al., 1996).

Mitochondrial inhibitors. Neuronal cultures were treated with $5 \mu \mathrm{M}$ carbonyl cyanide $p$-(trifluoromethoxy)phenylhydrazone (FCCP), $20 \mu \mathrm{M}$ FCCP, $2 \mu \mathrm{g} / \mu$ l oligomycin plus 5 or $20 \mu \mathrm{M}$ FCCP, $2 \mu \mathrm{M}$ rotenone, or 200 $\mathrm{nM}$ antimycin A during the $20 \mathrm{~min}$ incubation with TMRM. Inhibitors were also present during imaging. For the oligomycin-only treatment, the cells were incubated without drugs during a 20 min loading with TMRM and then transferred to medium containing oligomycin before imaging; thus cells were exposed to oligomycin for $10 \mathrm{~min}$ or less.

Quantitative imaging. Images were analyzed using MetaMorph software (Molecular Devices). TMRM images were thresholded to isolate the mitochondrial fluorescence from the rest of the image, and the fluorescence intensity was measured per square micrometer using the integrated morphometry analysis function. Cytoplasmic fluorescence was determined in hand-drawn regions a few micrometers from any mitochondrion. The diameter of a DRG axon from an E10-E11 embryo is $\sim 750$ $\mathrm{nm}$ and the diameter of mitochondria is $250 \mathrm{~nm}$, according to electron micrographs (Hollenbeck and Bamburg, 2003). The $\Delta \Psi_{\mathrm{m}}$ is proportional to the ratio of the [TMRM] on either side of the inner mitochondrial membrane. Thus, the ratio of the mitochondrial-to-cytoplasmic fluorescence in the same volume is proportional to $\Delta \Psi_{\mathrm{m}}$ (Ehrenberg et al., 1988; Diaz et al., 2000) and was determined using the following formula: $\left[\left(\mathrm{Fl}_{\text {mitochondria }}-(2 / 3) \mathrm{Fl}_{\text {cytoplasm }}\right) /(1 / 3) \mathrm{Fl}_{\text {cytoplasm }}\right]$. This volumecorrected fluorescence ratio is used throughout the text and figures and is referred to as $F_{\mathrm{m}} / F_{\mathrm{c}}$. Mitochondria located within the growth cone itself were separated into two different populations and $F_{\mathrm{m}} / F_{\mathrm{c}}$ was calculated with one of two formulas depending on their location within the growth cone and consistent with the dimensions of the mitochondria, axons, and growth cone as measured by electron microscopy. To determine the $F_{\mathrm{m}} / F_{\mathrm{c}}$ of mitochondria located in the proximal (phase dense) region of the growth cone, where the thickness is similar to the axon, the above calculation was used. The distal portions of the growth cone (bright under phase microscopy) are thinner than the axon and approximately the thickness of a mitochondrion, so the following formula was used to calculate the $F_{\mathrm{m}} / F_{\mathrm{c}}$ of mitochondria in those regions: $\left[\mathrm{Fl}_{\text {mitochondria }} /(1 / 3)\right.$ $\mathrm{Fl}$ cytoplasm $]$. The value of $F_{\mathrm{m}} / F_{\mathrm{c}}$ was used to determine the intracellular and intercellular variation in DRG neurons. As a measure of intercellular variation, the mean fluorescence ratio of all the mitochondria for each cell was determined giving a collection of cell means, and the SD of those cell means was determined. Intracellular variation was calculated by taking the SD of the mitochondrial fluorescence ratio for each cell to estimate variability and the mean of this collection of SDs was reported. For region comparisons, sections of the axon were categorized as being growth cones, branch points, or axon shafts. The region within $40 \mu \mathrm{m}$ of the axon-growth cone junction was labeled as "distal axon" (Morris and Hollenbeck, 1993). "Branch points" included the portions of axon within $40 \mu \mathrm{m}$ of the intersection, in all three directions. "Axon shaft" included areas $>40 \mu \mathrm{m}$ from either branch points or growth cones. Measurements taken in these three regions were compared with measurements made for mitochondria within the growth cones. Mitochondrial TMRM fluorescence ratio values among the four regions were compared with repeatedmeasures ANOVA (using SAS software) to assess intracellular variation in $F_{\mathrm{m}} / F_{\mathrm{c}}$.

The length and aspect ratio of individual mitochondria were measured 
in thresholded images using the integrated morphometry analysis function in MetaMorph. Measurements were collected from bath treatments of NGF, sema3A, 2-(4-morpholinyl)-8-phenyl-4H-1-benzopyran-4one (LY294002), and 1,4-diamino-2,3-dicyano-1,4-bis[2-aminophenylthio]butadiene (U0126) as well as treatments with NGF and sema3A beads. Morphology from images of control and treated cells gathered on the same day were compared by a $t$ test.

Mitochondrial movement comparisons. Cells were labeled with both TMRM and MitoTracker. First, an image of TMRM fluorescence was obtained as a measure of $F_{\mathrm{m}} / F_{\mathrm{c}}$. Then a series of six MitoTracker images taken at $10 \mathrm{~s}$ intervals was used to determine whether the mitochondrion was motile and direction of movement. The TMRM fluorescence of all stationary mitochondria in a single cell was averaged and compared with the fluorescence of moving mitochondria from the same cell using a paired $t$ test. Comparisons of TMRM fluorescence values between anterogradely and retrogradely moving mitochondria from any axon were compared with an unpaired $t$ test.

NGF and sema3A treatments. Cells were grown overnight in C medium, and then $1 \mathrm{~h}$ before the experiment the NGF was washed out by replacement with $\mathrm{F}$ medium lacking $\mathrm{NGF}$ and returned to $37^{\circ} \mathrm{C}$ before loading with TMRM. Sema3A application also required removal of NGFcontaining media in the same manner followed by $37^{\circ} \mathrm{C}$ incubation in $0.33 \mu \mathrm{g} / \mathrm{ml}$ sema3A-Fc (R\&D Systems) for at least $30 \mathrm{~min}$ and up to $2 \mathrm{~h}$. Incubation for $20 \mathrm{~min}$ with either 8 or $80 \mu \mathrm{M}$ tyrphostin $\alpha$-cyano-(3,5di-t-butyl-4-hydroxy)thiocinnamide (AG879) along with TMRM (Sigma-Aldrich) was used to block receptor tyrosine kinase signaling. To inhibit phosphatidylinositol-3 (PI3) kinase, cells were exposed to $100 \mu \mathrm{M}$ LY294002 (Sigma-Aldrich) during the $20 \mathrm{~min}$ incubation in TMRM. To inhibit mitogen-activated protein kinase (MAPK) signaling, cells were incubated in $20 \mu \mathrm{M}$ U0126 with TMRM for $20 \mathrm{~min}$. For focal exposure to NGF or sema3A, melamine beads with reactive carboxylate groups were coupled to carrier-free NGF, or sema3A-Fc (R\&D Systems) with carboiidimide using the manufacturer's protocol (Polysciences) as described previously (Gallo et al., 1997; Gallo and Letourneau, 1998; Chada and Hollenbeck, 2003, 2004). Two microliters of beads were rinsed in F12 medium containing $5 \mathrm{ng} / \mathrm{ml} \mathrm{NGF}$ for $5 \mathrm{~min}$ before being resuspended in $20 \mathrm{ml}$ of the same F12 medium. Medium with beads was applied to cultures in $6 \times 35 \mathrm{~mm}$ multiwell plates and these were incubated for at least 1 and up to $5 \mathrm{~h}$ at $37^{\circ} \mathrm{C}$ before being loaded with TMRM and examined under the microscope. Bead bioactivity was tested as described previously (Chada and Hollenbeck, 2003, 2004), by the active response of growth cones in turning toward NGF beads and away from sema3A beads. Only single beads adherent along the axon shaft were chosen for analysis, as described previously (Chada and Hollenbeck, 2003, 2004). To test for accumulation of mitochondria around a bead, two regions were compared: the $10 \mu \mathrm{m}$ of the axon in the immediate vicinity of the bead and a $10 \mu \mathrm{m}$ region of the axon $100 \mu \mathrm{m}$ away from the bead. Three regions of the axon were considered when comparing $F_{\mathrm{m}} / F_{\mathrm{c}}$ : the $10 \mu \mathrm{m}$ immediately adjacent to the bead, the $100 \mu \mathrm{m}$ region spanning $50 \mu \mathrm{m}$ on either side of the bead not including the previous region, and portions of the axon $>50 \mu \mathrm{m}$ away from the bead. The fluorescence ratios for all mitochondria $>50 \mu \mathrm{m}$ from the bead were averaged, and this value was then compared with each mitochondrion in the two regions close to the bead to normalize for cell-cell variability. All fluorescence values were normalized against the mean fluorescence value from the most distal region of the axon. Data from each cell were normalized individually to take intercellular variability into account.

\section{Results}

\section{Determining mitochondrial $F_{\mathrm{m}} / F_{\mathrm{c}}$ using TMRM}

Mitochondria use the potential energy stored in the $\Delta \Psi_{\mathrm{m}}$ for most mitochondrial functions including the production of ATP, take up or release of calcium or other ions, and import of proteins. A higher $\Delta \Psi_{\mathrm{m}}$ can potentially produce ATP, but also produces more reactive oxygen species (ROS). We previously used lipophilic cationic fluorescent dyes to specifically label, locate, and track mitochondria in live neurons (Morris and Hollenbeck, 1993, 1995; Overly et al., 1996; Chada and Hollenbeck, 2003,
2004). Here, we used TMRM, a rapidly equilibrating, relatively nontoxic, lipophilic cationic fluorescent dye (Farkas et al., 1989; Scaduto and Grotyohann, 1999) to label mitochondria and, via the ratio of mitochondrial-to-cytoplasmic fluorescence, to estimate the $\Delta \Psi_{\mathrm{m}}$ of individual organelles (Duchen et al., 1998; Mao and Kisaalita, 2004; H. M. Huang et al., 2005; Parihar and Brewer, 2007). To work at subquenching dye concentrations, in which mitochondrial-to-cytoplasmic TMRM fluorescence intensity ratio $\left(F_{\mathrm{m}} / F_{\mathrm{c}}\right)$ (as described in Materials and Methods) is proportional to the $\Delta \Psi_{\mathrm{m}}$, we loaded neurons with $20 \mathrm{nM}$ TMRM (Ward et al., 2000; Nakayama et al., 2002). Mitochondrial TMRM intensity alone reflects both the inner membrane potential and the cytoplasmic dye concentration, and the latter can vary with plasma membrane potential. Measuring the ratio of mitochondrial-to-cytoplasmic dye fluorescence, $F_{\mathrm{m}} / F_{\mathrm{c}}$, corrects for variations in cytoplasmic dye concentration and yields a value reflecting only the inner mitochondrial membrane potential. This method also allows a continuous measure of membrane potential rather than a binary, polarized/ depolarized measurement.

To verify the relationship between $F_{\mathrm{m}} / F_{\mathrm{c}}$ and $\Delta \Psi_{\mathrm{m}}$, we applied to dye-labeled cells a series of mitochondrial drugs with well characterized effects on respiration (Fig. 1). When oligomycin was used to inhibit $\mathrm{F}_{0} / \mathrm{F}_{1}$ ATPase, the $F_{\mathrm{m}} / F_{\mathrm{c}}$ increased $\sim 20 \%$ compared with controls. The proton ionophore FCCP alone decreased $F_{\mathrm{m}} / F_{\mathrm{c}}$ to $84 \%$ of control levels; FCCP treatment together with oligomycin decreased $F_{\mathrm{m}} / F_{\mathrm{c}}$ to $27 \%$. The modest effect of FCCP-alone treatment probably derives from reversal of the $\mathrm{F}_{0} / \mathrm{F}_{1}$ ATPase that can occur to maintain membrane potential in uncoupled cells (Leyssens et al., 1996; Takeda et al., 2004); this is supported by the much greater decrease in $F_{\mathrm{m}} / F_{\mathrm{c}}$ when FCCP and oligomycin are used together. Inhibition of complex I or III with rotenone or antimycin $\mathrm{A}$, respectively, decreased the $F_{\mathrm{m}} / F_{\mathrm{c}}$ to $40-60 \%$ of controls (Fig. $1 \mathrm{D}$ ). These predictable changes in fluorescence on treatment with mitochondrial inhibitors demonstrate that the $F_{\mathrm{m}} / F_{\mathrm{c}}$ of TMRM is proportional to $\Delta \Psi_{\mathrm{m}}$, allows reliable detection of changes in $\Delta \Psi_{\mathrm{m}}$, and also confirms that this loading regimen provides a subquenching dye concentration.

\section{Regional variation of $F_{\mathrm{m}} / F_{\mathrm{c}}$ in neurons}

To determine parameters that might alter $F_{\mathrm{m}} / F_{\mathrm{c}}$, we first looked at its range of variation in unperturbed cultured neurons. Previous experiments (Johnson et al., 1980, 1981) and our own observations have shown apparent variation in mitochondrial fluorescence among cells using various lipophilic cationic dyes. Variation in $\Delta \Psi_{\mathrm{m}}$ has also been noted within individual cells, and this may reflect subcellular control of mitochondrial respiration (Huang et al., 2004). We determined $F_{\mathrm{m}} / F_{\mathrm{c}}$ of individual mitochondria within many neurons in culture and compared intracellular and intercellular variation. Intercellular variation in $F_{\mathrm{m}} / F_{\mathrm{c}}$ was larger than intracellular variation, as can be seen in plots of a set of representative cells (Fig. 2A). The variation in $F_{\mathrm{m}} / F_{\mathrm{c}}$ between cells, measured as the mean of the SDs, was 4.25 and was much larger than the variation in $F_{\mathrm{m}} / F_{\mathrm{c}}$ within the mitochondria in each neuron, measured as the SD of a sample of mean mitochondrial $F_{\mathrm{m}} / F_{\mathrm{c}}$ from different neurons, which was 1.77. The intercellular variation in $F_{\mathrm{m}} / F_{\mathrm{c}}$ could reflect differences in cellular activities among neurons, such as axonal outgrowth or retraction, which would result in regulation of mitochondrial activity. In a larger population of 94 neurons with 1122 mitochondria, the mean $F_{\mathrm{m}} / F_{\mathrm{c}}$ was 11.0 with a slightly one-tailed unimodal distribution including a small population of highly polarized mitochondria (Fig. 2B). 

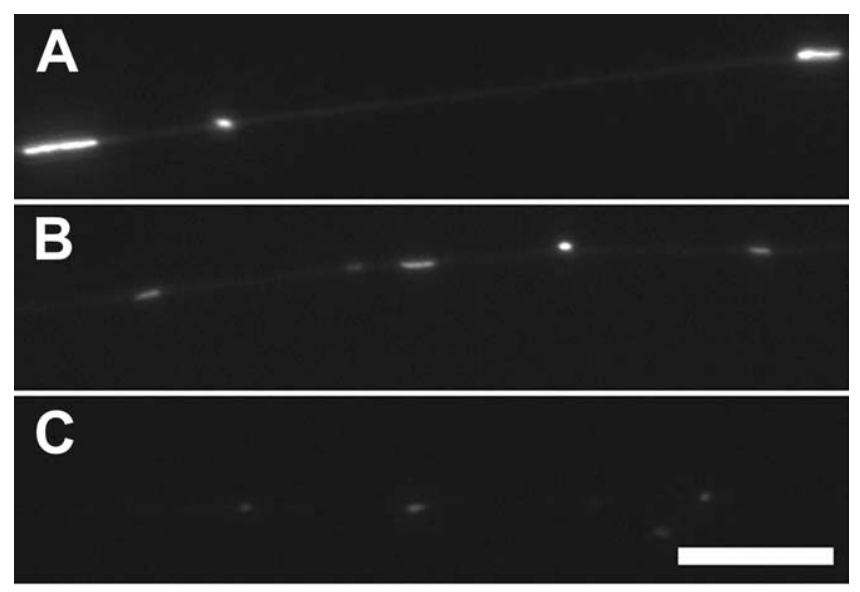

D

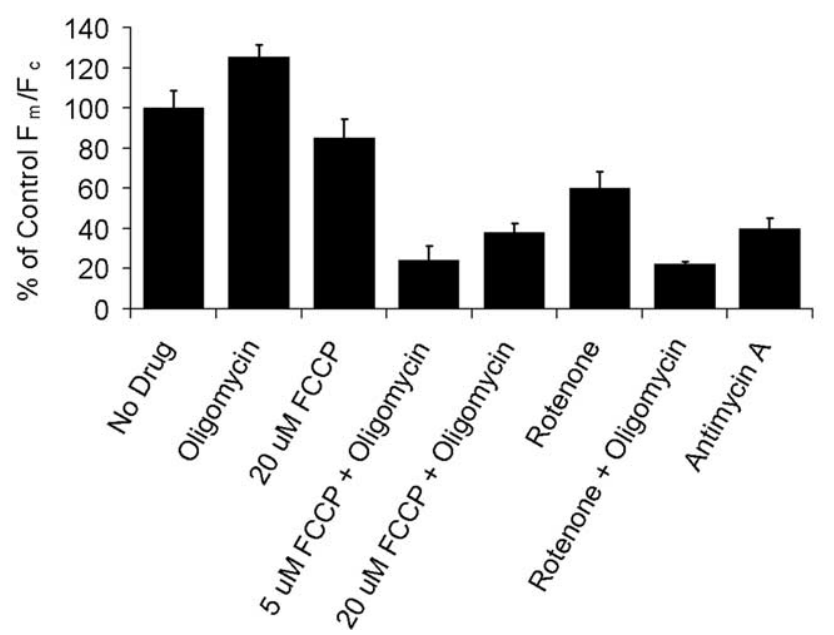

Figure 1. Mitochondrial TMRM fluorescence as a measure of $F_{\mathrm{m}} / F_{\mathrm{c}}$. Neurons were treated with uncoupler and/or inhibitors of electron transport and ATPase activity in the presence of TMRM. $F_{\mathrm{m}} / F_{\mathrm{c}}$ was assessed using the ratio of mitochondrial-to-cytoplasmic fluorescence as described in Materials and Methods. $\boldsymbol{A}$, Shown is a control cell with representative mitochondrial TMRM fluorescence. Axons treated with $2 \mu$ m rotenone $(\boldsymbol{B})$ or $2 \mu \mathrm{m}$ rotenone with $2 \mu \mathrm{g} / \mathrm{ml}$ oligomycin $(\boldsymbol{C}$ ) show diminished mitochondrial fluorescence. $\boldsymbol{A}$ appears overexposed because $\boldsymbol{A}-\boldsymbol{C}$ are displayed with identical exposures and image processing. Scale bar, $10 \mu \mathrm{m}$. $\boldsymbol{D}$, The TMRM fluorescence ratio of mitochondria was increased by oligomycin treatment, decreased by $\mathrm{FCCP}$, rotenone, or antimycin $\mathrm{A}$, and decreased the most with combined treatment of oligomycin and FCCP or rotenone. From left to right, $n=18,20,12,16,15,12,8$, and 10 neurons. Error bars show SEM.

We next determined whether this highly polarized subset was found preferentially in a particular region of the axon. Neurons have long been thought to exert control over mitochondrial position in response to local ATP demand, causing them to accumulate at, for example, active growth cones, synapses, and nodes of Ranvier (Hollenbeck and Saxton, 2005). To investigate whether neurons might also exert local control over $F_{\mathrm{m}} / F_{\mathrm{c}}$, we examined mitochondria in four functionally different regions of the axon: the axon shaft; the neighborhood of branch points, where mitochondria often accumulate; the distal axon close to growth cones, where mitochondrial transport and distribution are differentially regulated (Morris and Hollenbeck, 1993); and within the growth cones themselves, an anticipated region of higher ATP demand (Bernstein and Bamburg, 2003). To correct for intercellular variation in $F_{\mathrm{m}} / F_{\mathrm{c}}$, we compared values for all four regions by a repeated-measures ANOVA. There was no significant difference in $F_{\mathrm{m}} / F_{\mathrm{c}}$ among the axon shafts, branch
A

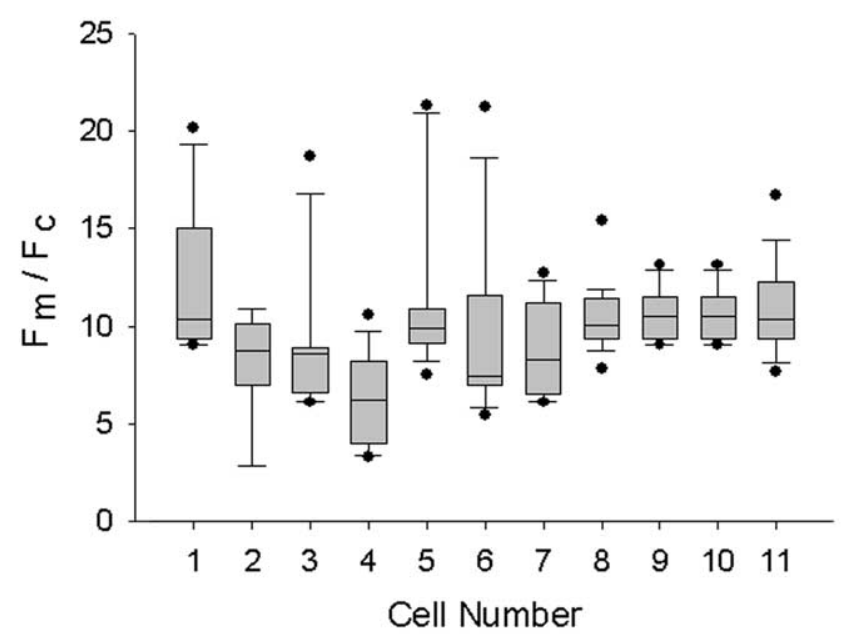

B

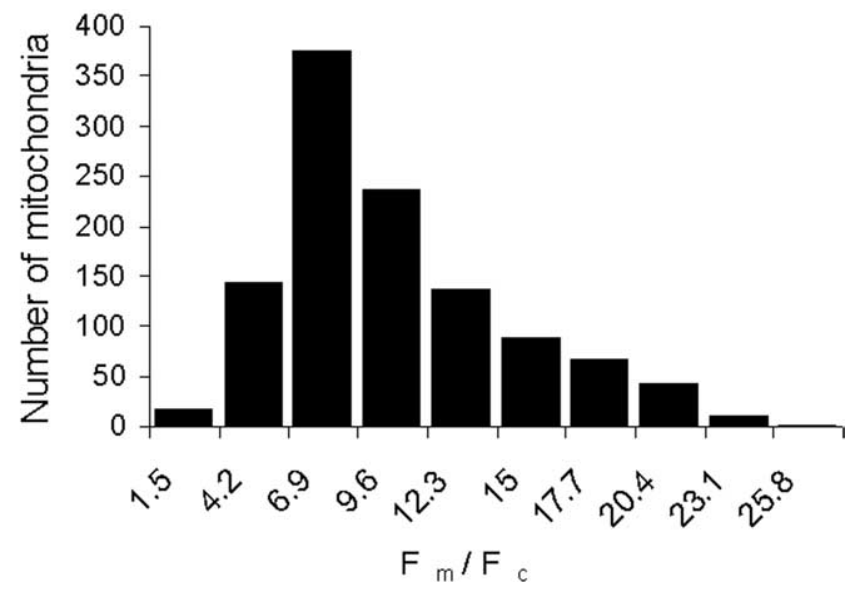

Figure 2. Samples of $F_{\mathrm{m}} / F_{\mathrm{c}}$ show greater intercellular than intracellular variation. $\boldsymbol{A}$, The mitochondrial fluorescence ratio distribution is shown for a representative sample of 11 neurons using a box plot and shows the mean (middle hash mark), 25th and 75th percentiles (top and bottom of box), 10th and 90th percentiles (top and bottom error bars), and any data points beyond the 10th and 90 th percentiles (top and bottom dots). $\boldsymbol{B}$, Histogram of $F_{\mathrm{m}} / F_{\mathrm{c}}$ shows a larger sample of 94 neurons with 1122 mitochondria but includes the sample of 11 neurons shown in $A$. The total population of $F_{\mathrm{m}} / F_{\mathrm{c}}$ does not show a normal distribution but has a tail with a higher $F_{\mathrm{m}} / F_{\mathrm{c}}$. All mitochondria were sampled from the axon shaft with 5-15 mitochondria per axon.

Table 1. Repeated-measures ANOVA

\begin{tabular}{llll}
\hline & Mean $\mathrm{FI}_{\mathrm{m}} / \mathrm{FI}_{\mathrm{c}}$ & $\mathrm{SD}$ & $N=$ cells $/$ mitos \\
\hline Comparison along axon & & & \\
$\quad$ Axon & 3.51 & 1.46 & $83 / 507$ \\
$\quad$ Branch point & 2.54 & 0.82 & $65 / 297$ \\
$\quad$ Distal axon & 3.78 & 1.67 & $49 / 318$ \\
$\quad F=0.94 ; p=0.39$ & & & \\
Comparison in growth cone & & & \\
$\quad$ Growth cone & 5.76 & 3.51 & $6 / 12$ \\
$\quad$ Distal axon & 4.53 & 2.03 & $6 / 34$ \\
$\quad F=48.84 ; p<0.001$ & & & \\
$\quad$ mitos, Mitochondria. & & &
\end{tabular}

points, or distal axons in these neurons (Table 1, "Comparison along axon"). However, the mitochondrial population found within growth cones had a mean $F_{\mathrm{m}} / F_{\mathrm{c}}$ that was significantly greater $(27 \%)$ than in surrounding regions (Table 1, "Compari- 
son in growth cone"). Although the difference in uncorrected fluorescence intensities between axonal and growth cone mitochondria was only modest, the corrected $F_{\mathrm{m}} / F_{\mathrm{c}}$, based on best measurements of thickness for these axons (see Materials and Methods), showed a significantly higher $F_{\mathrm{m}} / F_{\mathrm{c}}$ in the growth cone compared with the axon. Thus, although we found no correlation between $F_{\mathrm{m}} / F_{\mathrm{c}}$ and different regions of the axon, we conclude that growth cones were foci of higher $F_{\mathrm{m}} / F_{\mathrm{c}}$.

Because mitochondria are delivered to different regions of the axon by regulated transport (Hollenbeck and Saxton, 2005), it is possible that some of the intracellular heterogeneity in $F_{\mathrm{m}} / F_{\mathrm{c}}$ that we observed reflects differences in their transport. The small fraction of mitochondria with a significantly higher $F_{\mathrm{m}} / F_{\mathrm{c}}$ that are distributed throughout the axons might correspond to the minority of mitochondria that are moving at any one time. For example, moving and stationary mitochondria, or anterogradely moving and retrogradely moving mitochondria might differ because of composition, age, or other factors. Experiments in which neuronal mitochondria were labeled with the aggregating dye JC-1 have shown that mitochondria moving anterogradely predominantly have concentrated JC-1 to the point of J aggregation, resulting in red fluorescence, whereas those moving retrogradely displayed predominantly green fluorescence reflecting less concentrated, unaggregated dye. These authors concluded that $\Delta \Psi_{\mathrm{m}}$ varies with transport direction (Miller and Sheetz, 2004). We also found a difference in the JC-1 emission spectra of anterogradely and retrogradely moving mitochondria: the predominantly redfluorescing population in these axons spent $11 \%$ of its time moving anterogradely and 6\% moving retrogradely, and exhibited net anterograde movement, whereas the predominantly green population spent $5 \%$ of its time moving anterogradely and $6 \%$ moving retrogradely, yielding net retrograde movement. However, when we compared anterogradely, retrogradely, and stationary mitochondria quantitatively using the $F_{\mathrm{m}} / F_{\mathrm{c}}$ of TMRM, we obtained different results. We discerned among mitochondria moving anterogradely, retrogradely, and not at all by double-labeling cells with MitoTracker Green FM and TMRM, determining the $F_{\mathrm{m}} / F_{\mathrm{c}}$ of axonal mitochondria with the TMRM signal (Fig. $3 C$ ), and then observing them for $60 \mathrm{~s}$ using the MitoTracker signal to determine whether and in what direction they moved (Fig. $3 A, B)$. Paired $t$ tests showed no significant difference in $F_{\mathrm{m}} / F_{\mathrm{c}}$ between stationary and moving mitochondria, and no difference between mitochondria moving retrogradely and anterogradely (Fig. 3D). Thus, within our limits of resolution, $F_{\mathrm{m}} / F_{\mathrm{c}}$ does not vary with mitochondrial movement.

Axon guidance molecules affect $F_{\mathrm{m}} / F_{\mathrm{c}}$

Local regulation of $\Delta \Psi_{\mathrm{m}}$ could result from intracellular signaling events, perhaps to locally regulate ATP production, calcium sequestration, or generation of ROS as seen in other cell types (Duchen et al., 1998; Kuznetsov et al., 2004; Brown et al., 2006; Naga et al., 2007). Previous experiments have shown that focal NGF signaling along the axon attracts and retains mitochondria in the immediate vicinity of the stimulation, an effect mediated by the PI3 kinase and MAP kinase signaling pathways (Chada and Hollenbeck, 2003, 2004). This recruitment of mitochondrial function could be accentuated if the same stimuli not only retained them in the region but also increased their metabolic activity. To probe the effects of NGF signaling on $F_{\mathrm{m}} / F_{\mathrm{c}}$, we incubated the neurons with a receptor tyrosine kinase inhibitor, tyrphosin AG879. Tyrphostins inhibit the activity of receptor tyrosine kinases and $100 \mu \mathrm{M}$ tyrphostin 879 has been shown to prevent cell differentiation and block activation of all three major
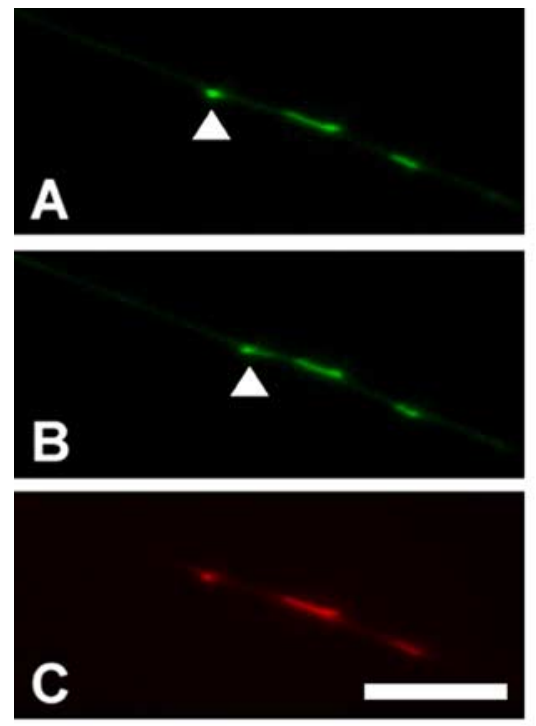

D

Comparison of $\mathrm{F}_{\mathrm{m}} / \mathrm{F}_{\mathrm{c}}$ in Moving Mitochondria

Mean $\mathrm{F}_{\mathrm{m}} / \mathrm{F}_{\mathrm{c}}$

SD

Anterograde versus Stationary $(P=0.52)$

$\begin{array}{lrr}\text { Moving mitochondria }(n=40) & 10.22 & 12.79 \\ \text { Stationary mitochondria }(n=133) & 9.27 & 5.67\end{array}$

Retrograde versus Stationary $(P=0.69)$

\begin{tabular}{lll} 
Moving mitochondria $(\mathrm{n}=28)$ & 8.20 & 6.59 \\
Stationary mitochondria $(\mathrm{n}=79)$ & 7.81 & 3.32 \\
\hline
\end{tabular}

$\begin{array}{lrr}\text { Anterograde versus Retrograde }(\mathbf{P}=\mathbf{0 . 4 4}) & \\ \text { Anterograde mitochondria }(n=28) & 10.22 & 12.79 \\ \text { Retrograde mitochondria }(n=40) & 8.20 & 6.59\end{array}$

Figure 3. Comparison of $F_{\mathrm{m}} / F_{\mathrm{c}}$ between anterogradely moving, retrogradely moving, and stationary mitochondria shows no difference in $F_{\mathrm{m}} / F_{\mathrm{c}}$. Mitochondria were stained with both Mitotracker and TMRM. $\boldsymbol{A}, \boldsymbol{B}$, Imaging of Mitotracker shows the position mitochondria along the axon; these two images were acquired 60 s apart. A single moving mitochondrion is highlighted with an arrow. $\boldsymbol{C}$, TMRM staining of the same field in $\boldsymbol{A}$ indicates $F_{\mathrm{m}} / F_{\mathrm{c}}$. Scale bar, $10 \mu \mathrm{m}$. $\boldsymbol{D}$, Comparisons of populations of mitochondria using a paired $t$ test shows that the $F_{\mathrm{m}} / F_{\mathrm{c}}$ does not vary between stationary and moving mitochondria, or between anterogradely and retrogradely moving mitochondria. $n=33$ and 21 cells for that containing anterogradely or retrogradely moving mitochondria, respectively.

downstream pathways of NGF without affecting EGF (epidermal growth factor) or PDGF, two other major tyrosine kinases of DRG neurons (Ohmichi et al., 1993; Rende et al., 2000). We found that brief treatment of neurons with $80 \mu \mathrm{M}$ tyrphostin diminished $F_{\mathrm{m}} / F_{\mathrm{c}}$ by $80 \%$, a large decrease that was comparable with that caused by combined treatment with oligomycin and proton ionophores. Even $8 \mu \mathrm{M}$ tyrphostin diminished $F_{\mathrm{m}} / F_{\mathrm{c}}$ by $60 \%$ (Fig. $4 D$ ), indicating that the maintenance of normal $F_{\mathrm{m}} / F_{\mathrm{c}}$ in these neurons depends strongly on receptor tyrosine kinase signaling probably but perhaps not entirely through NGF. Treated neurons appeared otherwise robust and mitochondria were not fragmented, indicating that the large decrease in $F_{\mathrm{m}} / F_{\mathrm{c}}$ was achieved without cell death or damage to the mitochondria. When we merely washed NGF out of the culture medium, the 


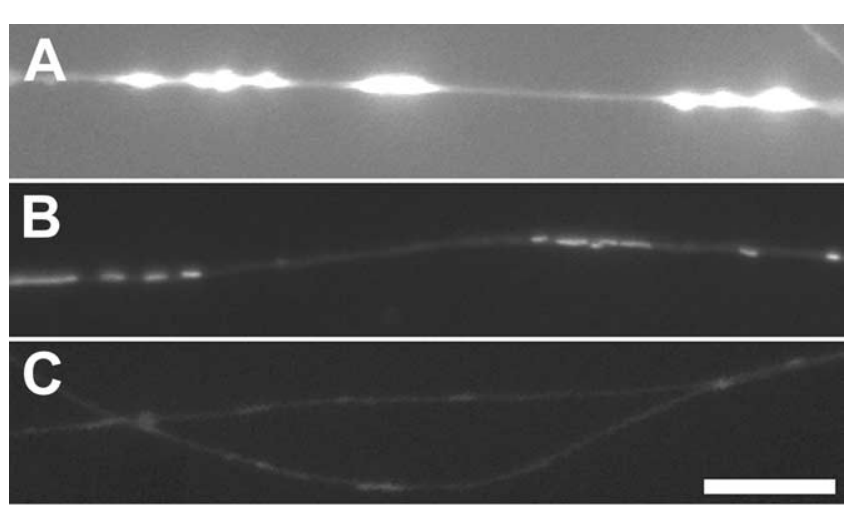

D

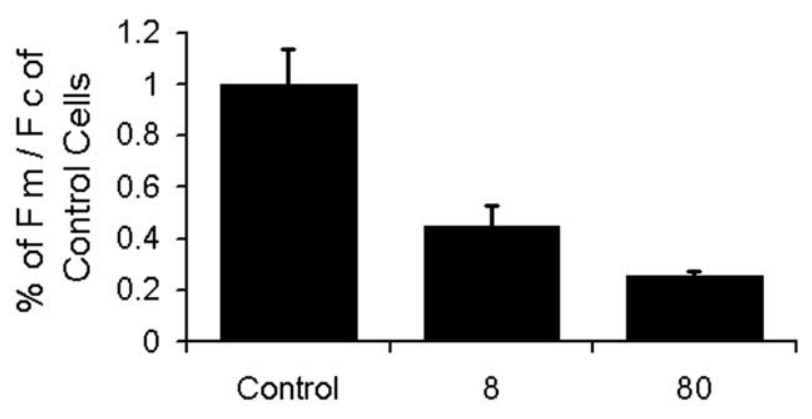

Tyrphostin AG879 concentration ( $\mu \mathrm{M})$

Figure 4. Inhibition of receptor tyrosine kinase signaling decreases $F_{\mathrm{m}} / F_{c}$. Cells were incubated for 20 min with the indicated concentrations of tyrphostin AG879 to block NGF signaling. Fluorescent images were taken of control $(\boldsymbol{A}), 8 \mu \mathrm{M}(\boldsymbol{B})$, or $80 \mu \mathrm{M}(\boldsymbol{C})$ tyrphostin-treated cells. The control images appear overexposed because images in $\boldsymbol{A}$-C have identical exposure times and image processing to render visible the mitochondria in the $80 \mu \mathrm{m}$ treatment. Scale bar, 10 $\mu \mathrm{m} . \boldsymbol{D}$, Tyrphostin AG879 decreased $F_{\mathrm{m}} / F_{\mathrm{c}}$ to 40 and $20 \%$ of control cells. For both treatments, $p<0.001$ compared with control. From left to right, $n=18,16$, and 12 neurons. Error bars Show SEM.

$F_{\mathrm{m}} / F_{\mathrm{c}}$ of axonal mitochondria still underwent a small but significant decrease (Fig. 5). Incubation of cultures with $100 \mu \mathrm{M}$ LY294002, a PI3 kinase inhibitor, decreased $F_{\mathrm{m}} / F_{\mathrm{c}}$ by $20 \%$, whereas incubation with $10 \mu \mathrm{M}$ U0126, a MAP kinase inhibitor, decreased it by $34 \%$ (Fig. 5), indicating that the effect of NGF on $F_{\mathrm{m}} / F_{\mathrm{c}}$ involves both PI3 kinase and MAPK signaling. However, incubation with both MAPK and PI3K inhibitors decreased $F_{\mathrm{m}} / F_{\mathrm{c}}$ the same amount as inhibiting MAPK alone, suggesting that these pathways intersect upstream of MAPK on the way to their mitochondrial target. None of these drug treatments altered mitochondrial length or morphology (data not shown) (see Materials and Methods) showing that the changes in fluorescence ratio reflect changes in membrane potential rather than geometry. When the cells were cultured in medium containing pyruvate instead of glucose, thereby bypassing glycolysis as a source of substrate, treatment with U0126 still decreased $F_{\mathrm{m}} / F_{\mathrm{c}}$. This indicates that effects of the MAPK pathway on $F_{\mathrm{m}} / F_{\mathrm{c}}$ do not involve regulation of glycolysis (Fig. 5).

Unlike NGF, which is an attractive cue for growth cones, semaphorins are repulsive guidance molecules. Exposure to semaphorin induces rearrangement of the cytoskeleton and causes the growth cone either to turn away from a source of semaphorin or to collapse completely (Castellani and Rougon, 2002). Semaphorin also influences downstream PIP3 signaling by activating phosphatase and tensin homolog deleted on chromosome 10 (PTEN) and decreasing PIP3 concentrations, and PI3

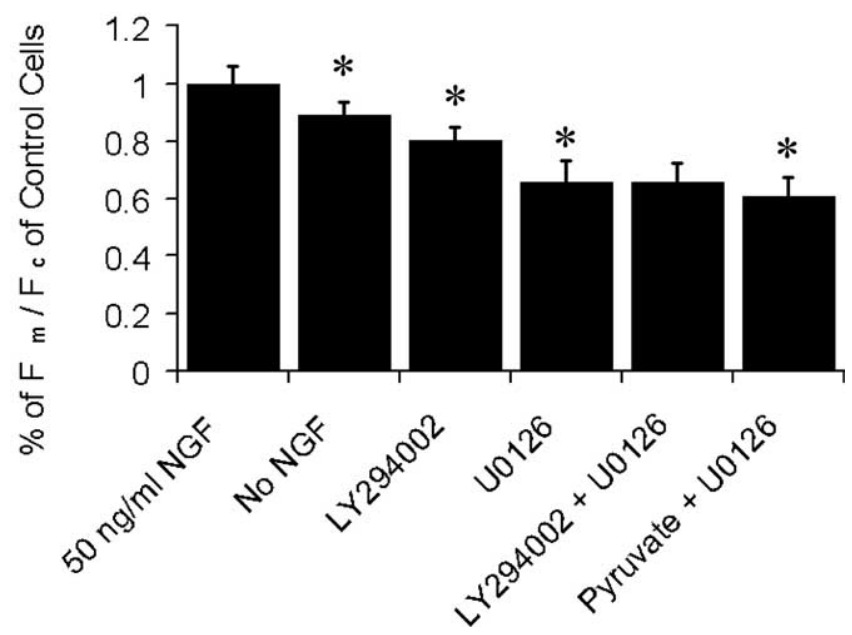

Figure 5. Global treatment of neurons with NGF and inhibitors of NGF pathways. Addition of $50 \mathrm{ng} / \mathrm{ml} \mathrm{NGF}$ to the culture medium increased the $F_{\mathrm{m}} / F_{\mathrm{c}}$. The effect of $50 \mathrm{ng} / \mathrm{ml}$ NGF is significantly diminished by adding $100 \mu \mathrm{M}$ PI3 kinase inhibitor LY294002 or $10 \mu \mathrm{M}$ MAPK inhibitor U0126. A combination of LY294992 and U0126 decreased $F_{\mathrm{m}} / F_{\mathrm{c}}$ only as much as U0126 alone. U0126 decreased $F_{\mathrm{m}} / F_{\mathrm{c}}$ in neurons cultured in pyruvate when compared with cells also cultured in pyruvate but not treated with U0126. From left to right, $n=26,22,18,17,24$, and 21 neurons. ${ }^{*} p<0.001$. Error bars show SEM.

kinase inactivation is required for semaphorin-induced growth cone collapse (Ming et al., 1999; Atwal et al., 2003; Chadborn et al., 2006). Incubation of neurons in sema3A in the absence of NGF resulted in a decrease in $F_{\mathrm{m}} / F_{\mathrm{c}}$ of $10 \%$ [normalized control, $1.00 \pm 0.049(n=27)$; sema3A, $0.90 \pm 0.058(n=25) ; p<0.01]$. In the presence of saturating NGF, sema3A treatment had no effect on $F_{\mathrm{m}} / F_{\mathrm{c}}$. As with drug treatments, NGF and sema3A did not induce changes in mitochondrial length or shape (see Materials and Methods).

Although neurons in culture experience a uniform exposure to nutrients and growth factors over their entire surface, in vivo they are exposed to trophic factors and guidance molecules locally or in gradients (Bandtlow et al., 1987; Kennedy et al., 2006). Thus, homogeneous exposure to growth factors could explain the surprisingly low intracellular variation in $F_{\mathrm{m}} / F_{\mathrm{c}}$ that we observed, whereas the higher density of receptors at the growth cone (Kim et al., 1979) could explain the higher $F_{\mathrm{m}} / F_{\mathrm{c}}$ of mitochondria there (Table 1). To provide the axons with a focal source of NGF or sema $3 \mathrm{~A}$ that would more closely mimic the exposure to guidance cues in vivo, we used beads covalently coupled to either NGF or sema3A. Several hours of contact with NGF beads can cause sprouting of new growth cones (Gallo and Letourneau, 1998). On a shorter timescale, NGF-coupled beads affect the transport of mitochondria, and mitochondria accumulate near sites of beadaxon contact (Chada and Hollenbeck, 2003, 2004) (see Fig. 7A) before new axons are formed. We found that mitochondria also accumulate in the immediate vicinity of sema3A-coupled beads compared with a region of the same size $100 \mu \mathrm{m}$ away from a bead (Fig. 6). Because both NGF and sema3A signaling affect mitochondrial transport and have an effect on $\Delta \Psi_{\mathrm{m}}$ when applied homogeneously to the cell, we asked whether $\Delta \Psi_{\mathrm{m}}$ of individual mitochondria is affected by local NGF or sema3A stimulation. Compared with control heat-inactivated beads, NGF beads caused an increase of $46 \%$ in $F_{\mathrm{m}} / F_{\mathrm{c}}$ in the $10 \mu \mathrm{m}$ of axon immediately adjacent to the bead (Fig. $7 C$ ), whereas sema3A beads caused a $63 \%$ increase in $F_{\mathrm{m}} / F_{\mathrm{c}}$. Mitochondria that were $>40 \mu \mathrm{m}$ away from sites of bead-axon contact showed no effect, 


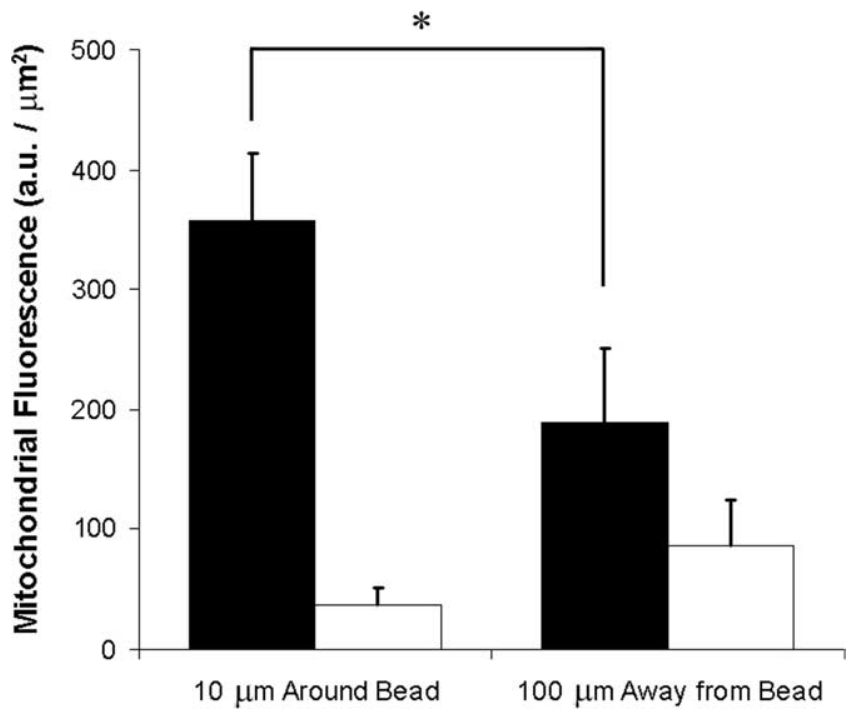

Figure 6. Mitochondria accumulate at sites of contact between the axon and semaphorin $3 \mathrm{~A}$-coated beads. The total TMRM fluorescence was compared between regions around either sema3A-coupled beads (black bars; $n=28$ cells) or heat-treated inactive beads (white bars; $n=20$ cells). The $10 \mu \mathrm{m}$ immediately surrounding the bead was compared with a $10 \mu \mathrm{m}$ region of the axon $100 \mu$ m away from the bead to be far enough away from any effect from the bead. Mitochondria were often closely adjacent to one another and could not be distinguished individually, so total fluorescence was compared between the two regions. Mitochondria accumulate around the sema $3 \mathrm{~A}$ beads shown by a significant increase in mitochondrial fluorescence when compared with heat-inactivated beads by a $t$ test. ${ }^{*} p<0.001$. Error bars show SEM.

whereas those 10-40 $\mu \mathrm{m}$ away from either NGF or sema3A beads showed an intermediate increase of $\sim 10 \%$. Both NGF and sema3A signaling were dependent on PI3 kinase and MAPK signaling, because the addition of the kinase inhibitors LY294002 or U0126 diminished the increase in $F_{\mathrm{m}} / F_{\mathrm{c}}$ in the $10 \mu \mathrm{m}$ of axon adjacent to the bead to statistical insignificance (Fig. 7C,D). The specific increase in $F_{\mathrm{m}} / F_{\mathrm{c}}$ adjacent to the beads indicates that neurons can regulate $F_{\mathrm{m}} / F_{\mathrm{c}}$ of individual mitochondria in response to molecular signals, but only within short distances.

\section{Discussion}

We assessed the proposition that neurons can respond to local demand for mitochondrial function by regulating mitochondrial metabolic state. We measured this quantitatively in intact sensory neurons using the cationic dye TMRM and taking its $F_{\mathrm{m}} / F_{\mathrm{c}}$ ratio to estimate the $\Delta \Psi_{\mathrm{m}}$ of mitochondria throughout the axons. We found that mitochondria in the growth cone of steady-state neurons, or close to a bead coated with guidance molecules, showed a significantly higher $F_{\mathrm{m}} / F_{\mathrm{c}}$ that is likely attributable to the stimulation of intracellular signaling pathways.

Most of what we know about the range of mitochondrial transmembrane potential comes from studies with isolated organelles (Scaduto and Grotyohann, 1999; Mattiasson et al., 2003) that show two different respiratory states, depending on substrate and ADP concentrations (Chance and Williams, 1955). The difference in $\Delta \Psi_{\mathrm{m}}$ between those two states in isolated mitochondria is only a fraction of the maximal $\Delta \Psi_{\mathrm{m}}$. The range of $\Delta \Psi_{\mathrm{m}}$ for mitochondria in a living cell is less certain, but there is some indication that it lies between the two states identified in vitro (Jekabsons and Nicholls, 2004). In sensory neurons, we found that treatment with either FCCP or oligomycin alone caused only a $\sim 20 \%$ change in $F_{m} / F_{c}$, implying that under normal intracellular conditions, as in vitro, modest changes in $F_{\mathrm{m}} / F_{\mathrm{c}}$ can correspond to large differences in respiratory activity. Our data also
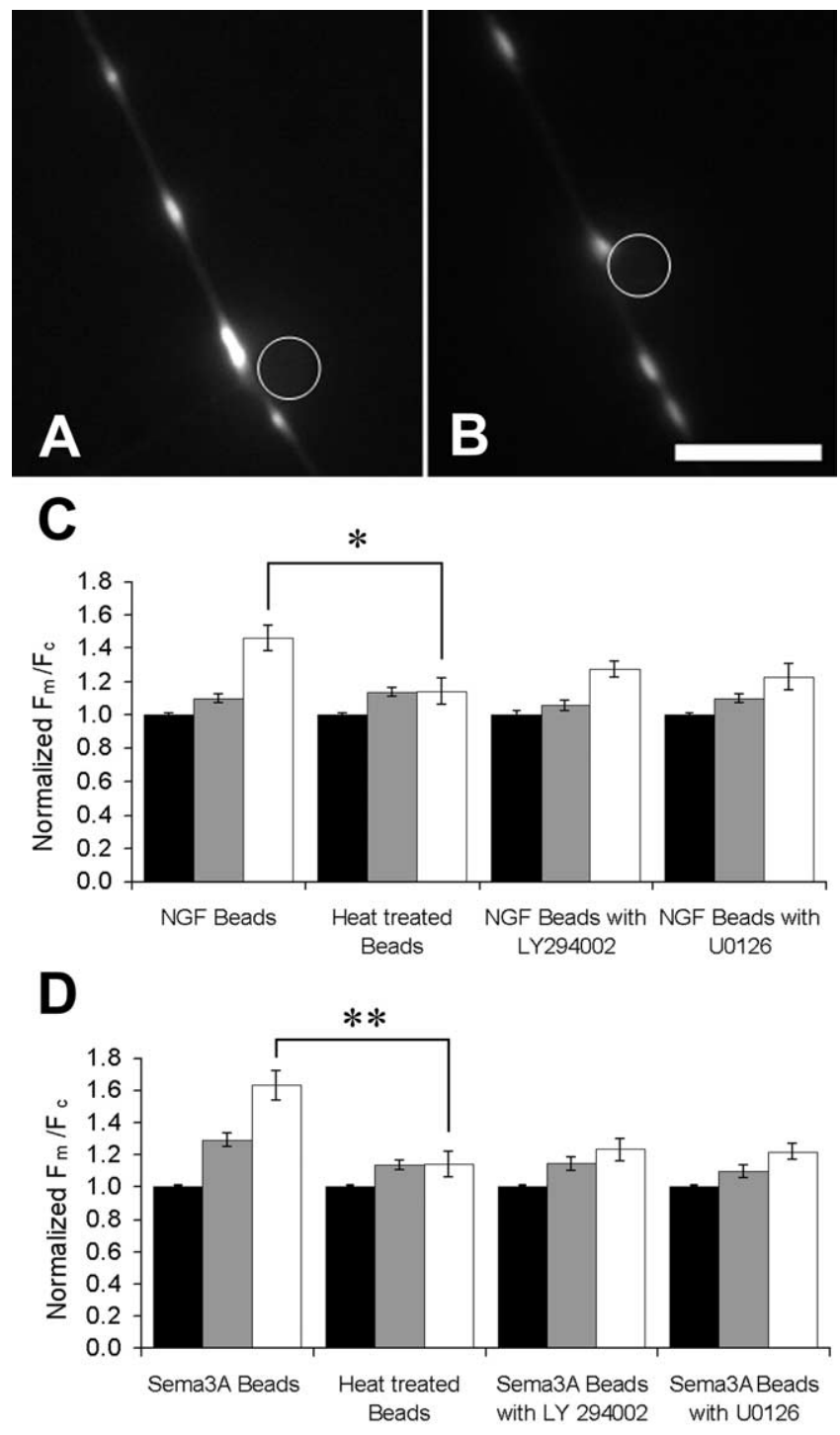

Figure 7. Axons incubated with NGF- or semaphorin 3A-coated beads display a local increase in $F_{\mathrm{m}} / F_{\mathrm{c}}$ in the region of axon immediately adjacent to the bead. Cells were rinsed and incubated in very low NGF medium and beads for $1 \mathrm{~h}$ before experiments. Fluorescence images show sites where an NGF-coated bead $(\boldsymbol{A})$ and a sema3A-coated bead $(\boldsymbol{B})$ are in contact with otherwise undistinguished regions of axons. Scale bar, $10 \mu \mathrm{m}$. $\boldsymbol{C}$, The distance between the mitochondria and the bead was measured and used to sort them into three groups: those in the $10 \mu \mathrm{m}$ of axon centered on the bead (white bars), those between 5 and $50 \mu \mathrm{m}$ away (gray bars), and those $>50 \mu \mathrm{m}$ from the bead (black bars). The mean $F_{\mathrm{m}} / F_{\mathrm{c}}$ of axonal mitochondria was increased within $50 \mu \mathrm{m}$ of the site of contact with an NGF bead, and this effect was even greater for mitochondria in the $10 \mu \mathrm{m}$ region centered on the contact site. The increase in $F_{\mathrm{m}} / F_{\mathrm{c}}$ near the NGF bead was partially blocked by either PI3 kinase inhibitor LY294002 or MAPK inhibitor U0126 for $20 \mathrm{~min}$. From left to right, $n=18,22,20$, and 16 neurons. $D$, The mitochondria in axons treated with sema $3 \mathrm{~A}$-coated bead were sorted according to distance from the site of axon-bead contact as just described. The mean $F_{\mathrm{m}} / F_{\mathrm{c}}$ of axonal mitochondria was also increased within $50 \mu \mathrm{m}$ of the site of contact with a sema3A bead, and this effect was even greater for mitochondria adjacent to the contact site. The increase in $F_{\mathrm{m}} / F_{\mathrm{c}}$ near the sema3A bead was partially blocked by PI3 kinase inhibitor LY294002 or MAPK inhibitor U0126. Heat denaturation of both kinds of beads eliminated their effect on $F_{\mathrm{m}} / F_{\mathrm{c}}$. From left to right, $n=18$, 17,21 , and 16 neurons. ${ }^{*} p<0.05 ;{ }^{* *} p<0.01$. Error bars show SEM.

show that $F_{\mathrm{m}} / F_{\mathrm{c}}$ can be decreased even further by combined treatment with several inhibitors of oxidative phosphorylation. However, a more profound effect than any of the conventional mitochondrial inhibitors was produced by blocking receptor tyrosine kinase and NGF signaling with tyrphostin AG879, suggesting that 
modulation of cellular signaling plays an important role in regulating $\Delta \Psi_{\mathrm{m}}$ and respiratory status in the neuron.

\section{Intrinsic variation in neuronal $\Delta \Psi_{\mathrm{m}}$}

Physiological intracellular variation in $\Delta \Psi_{\mathrm{m}}$ has been observed in non-neuronal cells (Johnson et al., 1980; O’Reilly et al., 2003) and clearly has functional significance in cells such as myocytes (Duchen et al., 1998). Quantitative evidence for different metabolic states among neuronal mitochondria comes from studies of cultured forebrain neurons, in which mitochondria in axons showed small, spontaneous oscillations between two levels of $\Delta \Psi_{\mathrm{m}}$ on a timescale of minutes (Buckman and Reynolds, 2001). Their function is unclear, and similar oscillations occur in vitro, in mitochondria isolated from brain (Vergun et al., 2003). In chick sensory neurons, we found relatively little difference in $F_{\mathrm{m}} / F_{\mathrm{c}}$ among mitochondria throughout an axon compared with the variation we saw among different neurons. For example, we did not observe the differences in $F_{\mathrm{m}} / F_{\mathrm{c}}$ between the distal axon (near the growth cone) and the rest of the axon that we had anticipated based on the range of growth cone effects on mitochondrial motility (Morris and Hollenbeck, 1993). This relative homogeneity in $F_{\mathrm{m}} / F_{\mathrm{c}}$ may derive from the uniform nutritional and growth factor environment experienced by neurons in culture, and thus it is possible that axons in situ show greater regional differences. Nonetheless, we found that mitochondria with a significantly higher $F_{\mathrm{m}} / F_{\mathrm{c}}$ exist in small numbers in the axon and are specifically concentrated in the growth cones. This is likely to reflect the high ATP demand in the growth cone, caused in part by actin and membrane turnover (Zakharenko and Popov, 2000; Bernstein and Bamburg, 2003), as well as the high density there of receptors for signaling ligands and the transient rises of cytoplasmic $\mathrm{Ca}^{2+}$ associated with growth cone function (Gomez and Spitzer, 2000; Soeda et al., 2002; Bolsover, 2005).

Variations in $F_{\mathrm{m}} / F_{\mathrm{c}}$ in a population of mitochondria might reflect not only differences in local ATP demand but also differences in mitochondrial status, with older or damaged mitochondria showing lower $F_{\mathrm{m}} / F_{\mathrm{c}}$. Studies using the aggregating mitochondrial dye JC-1 (Miller and Sheetz, 2004) have shown differences in fluorescent emission maxima that correlated with the direction of mitochondrial transport. Our results with JC-1 were essentially the same, but when we attempted to confirm this ratiometrically using a subquenching concentration of TMRM, we found no difference in $F_{\mathrm{m}} / F_{\mathrm{c}}$ among mitochondria moving in different directions. This discrepancy could result from the relatively slow equilibration and irreversible aggregation of JC-1, which can prevent it from accurately indicating the current $\Delta \Psi_{\mathrm{m}}$ of individual mitochondria (Smiley et al., 1991; Chinopoulos et al., 1999; Ward et al., 2000; Nakayama et al., 2002; Feldkamp et al., 2005). Thus, the red-emitting, J aggregated state of the JC-1 in anterogradely moving mitochondria could result from the cytoplasmic concentration of JC- 1 or the $\Delta \Psi_{\mathrm{m}}$ in the cell body before their entry into the axon, or to higher levels of ROS in the cell body, which can cause aggregation and red fluorescence of JC-1 in the matrix independent of $\Delta \Psi_{\mathrm{m}}$ (Chinopoulos et al., 1999). These factors would produce an artifactually high estimate of $\Delta \Psi_{\mathrm{m}}$ from red JC-1 fluorescence early in the axonal transport of the mitochondrion.

\section{$\Delta \Psi_{\mathrm{m}}$ and guidance molecule signaling}

Previous studies have indicated that growth factor signaling can produce an increase in the mean $\Delta \Psi_{\mathrm{m}}$ of the entire neuron (T. J. Huang et al., 2005), but little is known about how mitochondrial activity is regulated regionally, despite its potential importance in a large, asymmetric cell. We focally stimulated axons with NGF and sema3A, two signaling ligands known to affect growth cone activity, advance, and guidance (Gundersen and Barrett, 1980; Fan et al., 1993; Mann and Rougon, 2007). In addition, both regulate mitochondrial distribution in these axons (Chada and Hollenbeck, 2003, 2004) (Fig. 6). Here, we showed that they increase $F_{\mathrm{m}} / F_{\mathrm{c}}$ by a magnitude that is large by in vivo standards, at least for neurons and probably in general. However, the spatial range of the effect was surprisingly narrow. Mitochondria immediately adjacent to the site of NGF or sema3A stimulation showed a $40-50 \%$ increase in $F_{\mathrm{m}} / F_{\mathrm{c}}$, whereas mitochondria $10-50 \mu \mathrm{m}$ away showed a smaller effect that declined to insignificance beyond $50 \mu \mathrm{m}$. This was similar to the range of the effect of NGF stimulation on mitochondrial motility (Chada and Hollenbeck, 2004) but narrower than the effect of an active growth cone (Morris and Hollenbeck, 1993). This may explain why mitochondria with significantly higher $\Delta \Psi_{\mathrm{m}}$ in unperturbed neurons are found mainly within the growth cone itself.

Inhibitors of the PI3 kinase and MAP kinase pathways abolished the increase in $F_{\mathrm{m}} / F_{\mathrm{c}}$ produced by both focal and global NGF stimulation, suggesting that these downstream pathways mediate the regulation of mitochondrial potential. Because simultaneous inhibition of both pathways did not have an additive effect, NGF signaling probably converges on one pathway reaching before its target(s) in the mitochondria. The repulsive cue semaphorin has an ostensibly opposed function to NGF, but gave differing responses depending on how the cell was exposed to sema3A. The decrease in $\Delta \Psi_{\mathrm{m}}$ with global sema3A application could be through the action of PTEN, a phosphatase of PIP3 that reverses the effect of PI3 kinase. Growth cone turning or neuronal survival in the presence of both NGF and semaphorin signals may be attributable to the opposing function of PTEN and PI3 kinase acting on the same targets (Atwal et al., 2003; Dontchev and Letourneau, 2003; Wanigasekara and Keast, 2006). Consistent with this, we also found that global application of sema3A did not affect $F_{\mathrm{m}} / F_{\mathrm{c}}$ in the presence of saturating NGF. In contrast, local sema3A increased $F_{\mathrm{m}} / F_{\mathrm{c}}$, which is consistent with growth cone turning in vivo requiring increased ATP, but contrary to expectations if sema3A acted on $F_{\mathrm{m}} / F_{\mathrm{c}}$ exclusively through PTEN. The ability of LY294002 and U0126 to affect $\Delta \Psi_{\mathrm{m}}$ near sema3A beads suggests that there may be other mechanisms acting in local sema3A signaling. The overall importance of signaling downstream from RTKs (receptor tyrosine kinases) was underscored by the effect of tyrphostin treatment on the mitochondria: $F_{\mathrm{m}} / F_{\mathrm{c}}$ was diminished by $80 \%$, a magnitude matched in these neurons only with application of two separate mitochondrial poisons. None of the kinase inhibitors caused mitochondrial fragmentation, morphological change, axonal retraction, or any signs of cell death, indicating that treatment did not cause nonspecific insult. Thus, we conclude that kinase inhibition likely has a specific effect on $\Delta \Psi_{\mathrm{m}}$ regulation, causing mitochondria to change membrane potential or in some cases to depolarize profoundly.

These data demonstrate that the membrane potential of axonal mitochondria, like their distribution, can be regulated locally, but the identities of the signaling pathways and specific targets of $\Delta \Psi_{\mathrm{m}}$ regulation by kinases remain to be elucidated. Nonetheless, our data suggest some of their features. First, the effect of the PI3 kinase and MAPK inhibitors occurred within 20 $\mathrm{min}$, too fast to be explained by changes in mitochondrial protein synthesis, import, or degradation. Kinase regulation of glycolysis and the TCA cycle could affect $\Delta \Psi_{\mathrm{m}}$ (Hamilton et al., 2002; Long and Zierath, 2006), but the persistence of mitochondrial responses to NGF and sema3A in pyruvate-containing, glucose- 
free medium argues against this. It is more likely that the regulation of $\Delta \Psi_{\mathrm{m}}$ results from phosphorylation of target proteins that directly or indirectly alter mitochondrial activity. We suggest that the targets of regulation are likely to be mitochondrial phosphoproteins. Mitochondria contain kinases as well as candidate proteins for kinase activation or inhibition (Salvi et al., 2005; J. Lee et al., 2007; Tzatsos and Tsichlis, 2007). For example, kinase activity regulates proteins responsible for mitochondrial fusion and fission, which in turn interact with the complexes of the electron transport chain (Brooks et al., 2007; S. Lee et al., 2007; Zanna et al., 2008). There is also evidence that proteins of the electron transport chain itself may be phosphorylated, which could allow direct control of $\Delta \Psi_{\mathrm{m}}$ (Technikova-Dobrova et al., 2001). Other possibilities include protein phosphorylation of inner membrane transporters that could cause changes in matrix concentrations of ions such as potassium or interfere with the transport of other molecules such as adenine nucleotides. The potential similarities among the pathways and targets for the regulation of mitochondrial functions will be important areas of future study.

\section{References}

Atwal JK, Singh KK, Tessier-Lavigne M, Miller FD, Kaplan DR (2003) Semaphorin 3F antagonizes neurotrophin-induced phosphatidylinositol 3-kinase and mitogen-activated protein kinase kinase signaling: a mechanism for growth cone collapse. J Neurosci 23:7602-7609.

Bandtlow CE, Heumann R, Schwab ME, Thoenen H (1987) Cellular localization of nerve growth factor synthesis by in situ hybridization. EMBO J 6:891-899.

Bernstein BW, Bamburg JR (2003) Actin-ATP hydrolysis is a major energy drain for neurons. J Neurosci 23:1-6.

Berthold CH, Fabricius C, Rydmark M, Andersén B (1993) Axoplasmic organelles at nodes of Ranvier. I. Occurrence and distribution in large myelinated spinal root axons of the adult cat. J Neurocytol 22:925-940.

Bolsover SR (2005) Calcium signalling in growth cone migration. Cell Calcium 37:395-402.

Bray D, Money NP, Harold FM, Bamburg JR (1991) Responses of growth cones to changes in osmolality of the surrounding medium. J Cell Sci 98:507-515.

Bristow EA, Griffiths PG, Andrews RM, Johnson MA, Turnbull DM (2002) The distribution of mitochondrial activity in relation to optic nerve structure. Arch Ophthalmol 120:791-796.

Brooks C, Wei Q, Feng L, Dong G, Tao Y, Mei L, Xie ZJ, Dong Z (2007) Bak regulates mitochondrial morphology and pathology during apoptosis by interacting with mitofusins. Proc Natl Acad Sci U S A 104:11649-11654.

Brown MR, Sullivan PG, Geddes JW (2006) Synaptic mitochondria are more susceptible to $\mathrm{Ca}^{2+}$ overload than nonsynaptic mitochondria. J Biol Chem 281:11658-11668.

Buckman JF, Reynolds IJ (2001) Spontaneous changes in mitochondrial membrane potential in cultured neurons. J Neurosci 21:5054-5065.

Castellani V, Rougon G (2002) Control of semaphorin signaling. Curr Opin Neurobiol 12:532-541.

Chada SR, Hollenbeck PJ (2003) Mitochondrial movement and positioning in axons: the role of growth factor signaling. J Exp Biol 206:1985-1992.

Chada SR, Hollenbeck PJ (2004) Nerve growth factor signaling regulates motility and docking of axonal mitochondria. Curr Biol 14:1272-1276.

Chadborn NH, Ahmed AI, Holt MR, Prinjha R, Dunn GA, Jones GE, Eickholt BJ (2006) PTEN couples Sema3A signalling to growth cone collapse. J Cell Sci 119:951-957.

Chance B, Williams GR (1955) Respiratory enzymes in oxidative phosphorylation. III. The steady state. J Biol Chem 217:409-427.

Chinopoulos C, Tretter L, Adam-Vizi V (1999) Depolarization of in situ mitochondria due to hydrogen peroxide-induced oxidative stress in nerve terminals: inhibition of alpha-ketoglutarate dehydrogenase. J Neurochem 73:220-228.

De Vos KJ, Sable J, Miller KE, Sheetz MP (2003) Expression of phosphatidylinositol $(4,5)$ bisphosphate-specific pleckstrin homology domains alters direction but not the level of axonal transport of mitochondria. Mol Biol Cell 14:3636-3649.

Diaz G, Falchi AM, Gremo F, Isola R, Diana A (2000) Homogeneous longi- tudinal profiles and synchronous fluctuations of mitochondrial transmembrane potential. FEBS Lett 475:218-224.

Dontchev VD, Letourneau PC (2003) Growth cones integrate signaling from multiple guidance cues. J Histochem Cytochem 51:435-444.

Duchen MR, Leyssens A, Crompton M (1998) Transient mitochondrial depolarizations reflect focal sarcoplasmic reticular calcium release in single rat cardiomyocytes. J Cell Biol 142:975-988.

Ehrenberg B, Montana V, Wei MD, Wuskell JP, Loew LM (1988) Membrane potential can be determined in individual cells from the nernstian distribution of cationic dyes. Biophys J 53:785-794.

Fan J, Mansfield SG, Redmond T, Gordon-Weeks PR, Raper JA (1993) The organization of F-actin and microtubules in growth cones exposed to a brain-derived collapsing factor. J Cell Biol 121:867-878.

Farkas DL, Wei MD, Febbroriello P, Carson JH, Loew LM (1989) Simultaneous imaging of cell and mitochondrial membrane potentials. Biophys J 56:1053-1069.

Feldkamp T, Kribben A, Weinberg JM (2005) Assessment of mitochondrial membrane potential in proximal tubules after hypoxia-reoxygenation. Am J Physiol 288:F1092-F1102.

Gallo G, Letourneau PC (1998) Localized sources of neurotrophins initiate axon collateral sprouting. J Neurosci 18:5403-5414.

Gallo G, Lefcort FB, Letourneau PC (1997) The trkA receptor mediates growth cone turning toward a localized source of nerve growth factor. J Neurosci 17:5445-5454.

Gomez TM, Spitzer NC (2000) Regulation of growth cone behavior by calcium: new dynamics to earlier perspectives. J Neurobiol 44:174-183.

Gundersen RW, Barrett JN (1980) Characterization of the turning response of dorsal root neurites toward nerve growth factor. J Cell Biol 87:546-554.

Hamilton SR, O'Donnell JB Jr, Hammet A, Stapleton D, Habinowski SA, Means AR, Kemp BE, Witters LA (2002) AMP-activated protein kinase kinase: detection with recombinant AMPK alphal subunit. Biochem Biophys Res Commun 293:892-898.

He Y, Baas PW (2003) Growing and working with peripheral neurons. Methods Cell Biol 71:17-35.

Hollenbeck PJ, Bamburg JR (2003) Comparing the properties of neuronal culture systems: a shopping guide for the cell biologist. Methods Cell Biol $71: 1-16$.

Hollenbeck PJ, Saxton WM (2005) The axonal transport of mitochondria. J Cell Sci 118:5411-5419.

Huang HM, Fowler C, Zhang H, Gibson GE (2004) Mitochondrial heterogeneity within and between different cell types. Neurochem Res 29:651-658.

Huang HM, Fowler C, Xu H, Zhang H, Gibson GE (2005) Mitochondrial function in fibroblasts with aging in culture and/or Alzheimer's disease. Neurobiol Aging 26:839-848.

Huang TJ, Verkhratsky A, Fernyhough P (2005) Insulin enhances mitochondrial inner membrane potential and increases ATP levels through phosphoinositide 3-kinase in adult sensory neurons. Mol Cell Neurosci 28:42-54.

Jekabsons MB, Nicholls DG (2004) In situ respiration and bioenergetic status of mitochondria in primary cerebellar granule neuronal cultures exposed continuously to glutamate. J Biol Chem 279:32989-33000.

Johnson LV, Walsh ML, Chen LB (1980) Localization of mitochondria in living cells with rhodamine 123. Proc Natl Acad Sci U S A 77:990-994.

Johnson LV, Walsh ML, Bockus BJ, Chen LB (1981) Monitoring of relative mitochondrial membrane potential in living cells by fluorescence microscopy. J Cell Biol 88:526-535.

Kennedy TE, Wang H, Marshall W, Tessier-Lavigne M (2006) Axon guidance by diffusible chemoattractants: a gradient of netrin protein in the developing spinal cord. J Neurosci 26:8866-8874.

Kim SU, Hogue-Angeletti R, Gonatas NK (1979) Localization of nerve growth factor receptors in sympathetic neurons cultured in vitro. Brain Res 168:602-608.

Kuznetsov AV, Usson Y, Leverve X, Margreiter R (2004) Subcellular heterogeneity of mitochondrial function and dysfunction: evidence obtained by confocal imaging. Mol Cell Biochem 256-257:359-365.

Lee J, Xu Y, Chen Y, Sprung R, Kim SC, Xie S, Zhao Y (2007) Mitochondrial phosphoproteome revealed by an improved IMAC method and MS/MS/ MS. Mol Cell Proteomics 6:669-676.

Lee S, Jeong SY, Lim WC, Kim S, Park YY, Sun X, Youle RJ, Cho H (2007) Mitochondrial fission and fusion mediators, hFis1 and OPA1, modulate cellular senescence. J Biol Chem 282:22977-22983. 
Leyssens A, Nowicky AV, Patterson L, Crompton M, Duchen MR (1996) The relationship between mitochondrial state, ATP hydrolysis, $\left[\mathrm{Mg}^{2+}\right] \mathrm{i}$ and $\left[\mathrm{Ca}^{2+}\right] \mathrm{i}$ studied in isolated rat cardiomyocytes. J Physiol 496:111-128.

Li Z, Okamoto K, Hayashi Y, Sheng M (2004) The importance of dendritic mitochondria in the morphogenesis and plasticity of spines and synapses. Cell 119:873-887.

Long YC, Zierath JR (2006) AMP-activated protein kinase signaling in metabolic regulation. J Clin Invest 116:1776-1783.

Malaiyandi LM, Honick AS, Rintoul GL, Wang QJ, Reynolds IJ (2005) $\mathrm{Zn}^{2+}$ inhibits mitochondrial movement in neurons by phosphatidylinositol 3-kinase activation. J Neurosci 25:9507-9514.

Mann F, Rougon G (2007) Mechanisms of axon guidance: membrane dynamics and axonal transport in semaphorin signalling. J Neurochem 102:316-323.

Mao C, Kisaalita WS (2004) Determination of resting membrane potential of individual neuroblastoma cells (IMR-32) using a potentiometric dye (TMRM) and confocal microscopy. J Fluoresc 14:739-743.

Martin R, Vaida B, Bleher R, Crispino M, Giuditta A (1998) Protein synthesizing units in presynaptic and postsynaptic domains of squid neurons. J Cell Sci 111:3157-3166.

Mattiasson G, Friberg H, Hansson M, Elmér E, Wieloch T (2003) Flow cytometric analysis of mitochondria from CA1 and CA3 regions of rat hippocampus reveals differences in permeability transition pore activation. J Neurochem 87:532-544.

Miller KE, Sheetz MP (2004) Axonal mitochondrial transport and potential are correlated. J Cell Sci 117:2791-2804.

Ming G, Song H, Berninger B, Inagaki N, Tessier-Lavigne M, Poo M (1999) Phospholipase C-gamma and phosphoinositide 3-kinase mediate cytoplasmic signaling in nerve growth cone guidance. Neuron 23:139-148.

Morfini G, Szebenyi G, Elluru R, Ratner N, Brady ST (2002) Glycogen synthase kinase 3 phosphorylates kinesin light chains and negatively regulates kinesin-based motility. EMBO J 21:281-293.

Morfini G, Szebenyi G, Brown H, Pant HC, Pigino G, DeBoer S, Beffert U, Brady ST (2004) A novel CDK5-dependent pathway for regulating GSK3 activity and kinesin-driven motility in neurons. EMBO J 23:2235-2245.

Morris RL, Hollenbeck PJ (1993) The regulation of bidirectional mitochondrial transport is coordinated with axonal outgrowth. J Cell Sci 104:917-927.

Morris RL, Hollenbeck PJ (1995) Axonal transport of mitochondria along microtubules and F-actin in living vertebrate neurons. J Cell Biol 131:1315-1326.

Mueller BK (1999) Growth cone guidance: first steps towards a deeper understanding. Annu Rev Neurosci 22:351-388.

Mutsaers SE, Carroll WM (1998) Focal accumulation of intra-axonal mitochondria in demyelination of the cat optic nerve. Acta Neuropathol 96:139-143.

Naga KK, Sullivan PG, Geddes JW (2007) High cyclophilin D content of synaptic mitochondria results in increased vulnerability to permeability transition. J Neurosci 27:7469-7475.

Nakayama S, Sakuyama T, Mitaku S, Ohta Y (2002) Fluorescence imaging of metabolic responses in single mitochondria. Biochem Biophys Res Commun 290:23-28.

Nicholls DG, Budd SL (2000) Mitochondria and neuronal survival. Physiol Rev 80:315-360.

Ohmichi M, Pang L, Ribon V, Gazit A, Levitzki A, Saltiel AR (1993) The tyrosine kinase inhibitor tyrphostin blocks the cellular actions of nerve growth factor. Biochemistry 32:4650-4658.

O'Reilly CM, Fogarty KE, Drummond RM, Tuft RA, Walsh JV Jr (2003) Quantitative analysis of spontaneous mitochondrial depolarizations. Biophys J 85:3350-3357.

Overly CC, Rieff HI, Hollenbeck PJ (1996) Organelle motility and metabo- lism in axons vs dendrites of cultured hippocampal neurons. J Cell Sci 109:971-980.

Palay SL (1956) Synapses in the central nervous system. J Biophys Biochem Cytol 2:193-202.

Parihar MS, Brewer GJ (2007) Mitoenergetic failure in Alzheimer disease. Am J Physiol 292:C8-C23.

Ratner N, Bloom GS, Brady ST (1998) A role for cyclin-dependent kinase(s) in the modulation of fast anterograde axonal transport: effects defined by olomoucine and the APC tumor suppressor protein. J Neurosci 18:7717-7726.

Rende M, Brizi E, Conner J, Treves S, Censier K, Provenzano C, Taglialatela G, Sanna PP, Donato R (2000) Nerve growth factor (NGF) influences differentiation and proliferation of myogenic cells in vitro via TrKA. Int J Dev Neurosci 18:869-885.

Ruthel G, Hollenbeck PJ (2003) Response of mitochondrial traffic to axon determination and differential branch growth. J Neurosci 23:8618-8624.

Salvi M, Brunati AM, Toninello A (2005) Tyrosine phosphorylation in mitochondria: a new frontier in mitochondrial signaling. Free Radic Biol Med 38:1267-1277.

Scaduto RC Jr, Grotyohann LW (1999) Measurement of mitochondrial membrane potential using fluorescent rhodamine derivatives. Biophys J 76:469-477.

Scheffler IE (1999) Mitochondria, Ed 1. New York: Wiley.

Smiley ST, Reers M, Mottola-Hartshorn C, Lin M, Chen A, Smith TW, Steele GD Jr, Chen LB (1991) Intracellular heterogeneity in mitochondrial membrane potentials revealed by a J-aggregate-forming lipophilic cation JC-1. Proc Natl Acad Sci U S A 88:3671-3675.

Soeda H, Tatsumi H, Kozawa Y, Mishima H, Imai K, Katayama Y (2002) Functional characterization of calcium channels localized on the growth cones of cultured rat dorsal root ganglion cells. Neurosci Lett 325:5-8.

Takeda Y, Pérez-Pinzón MA, Ginsberg MD, Sick TJ (2004) Mitochondria consume energy and compromise cellular membrane potential by reversing ATP synthetase activity during focal ischemia in rats. J Cereb Blood Flow Metab 24:986-992.

Technikova-Dobrova Z, Sardanelli AM, Speranza F, Scacco S, Signorile A, Lorusso V, Papa S (2001) Cyclic adenosine monophosphate-dependent phosphorylation of mammalian mitochondrial proteins: enzyme and substrate characterization and functional role. Biochemistry 40:13941-13947.

Tzatsos A, Tsichlis PN (2007) Energy depletion inhibits phosphatidylinositol 3-kinase/Akt signaling and induces apoptosis via AMP-activated protein kinase-dependent phosphorylation of IRS-1 at Ser-794. J Biol Chem 282:18069-18082.

Vergun O, Votyakova TV, Reynolds IJ (2003) Spontaneous changes in mitochondrial membrane potential in single isolated brain mitochondria. Biophys J 85:3358-3366.

Verstreken P, Ly CV, Venken KJ, Koh TW, Zhou Y, Bellen HJ (2005) Synaptic mitochondria are critical for mobilization of reserve pool vesicles at Drosophila neuromuscular junctions. Neuron 47:365-378.

Wanigasekara Y, Keast JR (2006) Nerve growth factor, glial cell line-derived neurotrophic factor and neurturin prevent semaphorin 3A-mediated growth cone collapse in adult sensory neurons. Neuroscience 142:369-379.

Ward MW, Rego AC, Frenguelli BG, Nicholls DG (2000) Mitochondrial membrane potential and glutamate excitotoxicity in cultured cerebellar granule cells. J Neurosci 20:7208-7219.

Zakharenko S, Popov S (2000) Plasma membrane recycling and flow in growing neurites. Neuroscience 97:185-194.

Zanna C, Ghelli A, Porcelli AM, Karbowski M, Youle RJ, Schimpf S, Wissinger B, Pinti M, Cossarizza A, Vidoni S, Valentino ML, Rugolo M, Carelli V (2008) OPA1 mutations associated with dominant optic atrophy impair oxidative phosphorylation and mitochondrial fusion. Brain 131:352-367. 